\title{
MARIAZINHA MESSEDER: UMA VIDA CENTE- NÁRIA NO CONTEXTO DO NÚMERO JUBILAR DA REVISTA DE HISTÓRIA.
}

\author{
MARIA REGINA \\ do Departamento de História da Universidade de \\ São Paulo.
}

O impacto da notícia estaria na própria originalidade. Uma senhora completa 100 anos. Uma revista publica o número 100 .

Pergunta-se, onde? Quando?

O primeiro fato aconteceu na cidade do Salvador, aos 15 de dezembro de 1974, onde Maria da Glória Câmara Messeder (d. Mariazinha), festejou na intimidade da família, o natalício centenário.

Foi uma festa sintonizada com a aniversariante: discreta, operosa, alegre, auditiva. Especificamente aberta à palavra de Deus. No sentido de uma prontidão absoluta, sem limites, ao Seu serviço naqueles que a procuram.

Essa atitude fundamental de uma vida cristã, poderia ser captada no convite para uma ação de graças comunitária. Que se realizou às 11 horas, na Igreja de Nossa Senhora da Vitória (1), matriz da pa-

(1). - A Igreja de Nossa Senhora da Vitória, um dos venerandos templos da capital, cuja religiosidade popular, acionou a lenda de "uma igreja para cada dia do ano"; pode ser considerada o embrião do bairro central, que the herdou o nome, Vitória. Neste periódico justifica-se lembrar que, entre outras especificidades da histórica Igreja de Nossa Senhora da Vitória, destaca-se uma lápide com a inscrição seguinte:

"Aqui jaz Affonço Rodrigues, natural de Obidos o primeiro homem que se cazou nesta terra falleceo na era de 1561 ".

Pouca gente sabe que se trata do primeiro casamento sacralisado, conhecido. O celebrante foi um dos dois padres franciscanos que, na companhia de Martim Afonso de Souza, pousaram em terras do patriarca Caramurú. Oportunidade $\mathrm{cm}$ que efetuaram batisados e casamentos em quase todo o clá, inclusive duas das filhas do casal, Catarina (Paraguaçú) e Diogo (Caramurú). (In Documentos Históricos. Rio de Janeiro, Biblioteca Nacional, vol. XXXVI; Frei Odulfo Van der Vatten, Principios da Igreja no Brasil, pág. 46). 
róquia a que d. Mariazinha está vinculada. Ontem, participando ativamente das obras assistenciais, da assembléia dos fieis. Hoje, no silêncio do amplo apartamento (2), ao imperativo da idade, soma-se a vigilância da filha dedicada, do genro invulgar. Foram eles, os dois, que a ampararam no retorno à Igreja, no dia do seu jubileu. Com humildade, aceitou a honra de uma poltrona junto ao altar, aguardando a chegada do sacerdote, para o início da Santa Missa, uma estupenda cerimônia comunitária. Pois, o padre Frei Mariano Duklemans não ficou oficiando sozinho, dialogou com a comunidade (comum unidade de Fé, de Amor e de Esperança) integrada pelos membros de uma mesma famíla, efetiva e afetiva. Concientizados da carga do "tempo presente", sugeriu-se e, todos concordaram, que se encerrasse a cerimônia litúrgica com $A$ Montanha de Roberto Carlos.

Prenúncio do re-encontro que se seguiu na chácara em Brotas (3), onde a festa teve continuidade: almoço informal, serestas, fotos e mais fotos, com a participação de d. Mariazinha espantosamente lúcida e feliz. Dos retratos para o album da família, destaque-se: um ampliado, parâmetro de uma rápida análise, no centro, a matriarca, d. Mariazinha e Frei Mariano, autêntico filho do Patriarca de Assis, simbolizando a fraternidade universal. Em categorias crescentes, em vagas indisciplinadas, nove trinetos, cinquenta e um bisnetos, trinta e seis netos, duas noras, um genro e três filhos. Outra foto, lado a lado, d. Mariazinha, os filhos Augusto e Adriano, atrás a única filha Maria de Lourdes e o marido Isaias Santos de Carvalho, considerado filho e irmão.

Dir-se-ia espantoso, mas não impossivel que esses três filhos a tivessem presenteado com noventa e um descendentes. Esclareça-se que do casamento de Maria da Glória Grasse Câmara com José Eduardo Coelho Messeder, na mesma capital baiana aos 17 de maio de 1840, nasceram sete filhos (seis homens e uma mulher), que lhe deram noras e netos. Aconteceu que "... à semelhança de Maria, Nossa Senhora", ...) "José partiu primeiro" (4), ainda quatro dos sete filhos. Mais um neto. Outros bisnetos.

(2). - Rua Banco dos Ingleses, n. 12,5 and. Salvador, BA.

(3). - Brotas, hoje um dos bairros mais residenciais da capital bahiana, ainda conserva algumas de suas chácaras. Remanecente da época em que significava um refúgio bucólico, para fins de semana, ou férias prolongadas. Lá do seu sítio, as creanças de ontem, brincavam de contar os saveiros do porto, do alto, pareciam caixas de fósforos. Brotas bahiana teria parentesco com algumas de suas co-irmãs: Tremembé paulistana, Gávea carioca.

(4). - José Eduardo Coelho Messeder, faleceu em 24 de janeiro de 1947. Seis anos depois da comemoração das "Bodas de Ouro", pois o casamento aconteceu aos 17 de maio de 1890, na casa dos pais da noiva: Aristides Amâncio de Moura e Câmera e Elisa Adelaide Grasse Câmera, - na capital da Bahia. 
Pergunta-se, qual o segredo dessa vida de 100 anos?

A resposta poderia estar na mensagem enviada pela monja beneditina aqui de São Paulo (5), lida por outra neta, lá em Salvador, de que se transcreverá o trecho seguinte:

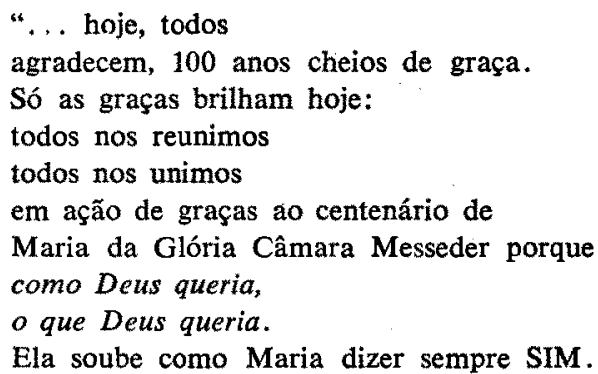

(L. M.)" (6).

Quanto à segunda problemática consulte-se os ANAIS desta paulistana cidade, onde deve estar registrado um outro centenário: Revista de História, São Paulo, L (100), outubro-dezembro, 1974.

Detendo-se mais atentamente captar-se-ia a mensagem: periódico trimestral, de publicação ininterrupta, desde 1950, (ano do seu nascedouro), por obra e graça de um homem, seu diretor, fundador e mantenedor (esclareça-se que a Faculdade de Filosofia, Letras e Ciências Humanas da Universidade de São Paulo, fornece o papel, sem nenhum privilégio, pois idêntica concessão abre-se a professores credenciados dos seus muitos departamentos que se disponham a publicar periódicos. Todas as demais despesas correm por conta do editor).

Retomando o fio do código, pode-se sentir a realidade, do objetivo que, ontem e hoje, especificam a Revista de História.

"... oferecer aos estudiosos uma oportunidade de divulgação sistemática das pesquisas que o amor ao estudo e a dedicação ao magistério propicia..." (7).

(5). - Abadia de Santa Maria - a rua São Carlos do Pinhal, n. 424 - Bela Vista, 0133, São Paulo.

(6). - L. M. (Lícia Maria), filha do saudoso Carlos Lúcio Alves e da historiadora Marieta Alves, respeitada no país e no estrangeiro. Dentre as muitas pesquisas originais, destaque-se a análise da série "Armadores na Bahia no século XVIII", vem sendo publicada neste periódico. L. M. há mais de vinte e cinco anos, fez profissão monástica na Abadia de Santa Maria, recebendo o nome de Irmã Plácida Alves OSB.

(7) . - Simões de Paula (Eurípedes), NOSSO PROGRAMA - Revista de História, São Paulo, I (1), jan.-mar. 1950. 
Concientizado de suas limitações, Eurípedes Simões de Paula, o fundador procura desculpar-se:

“... tal divulgação não possa corresponder, inteiramente aos anseios dos jovens pesquisadores, talvez pudesse encoraja-los e estimula-los..." (8).

Seria um paradoxo reproduzir tais idéias quando se foca o duplo centenário?

Sei lá, continuando a re-leitura do "Nosso Programa", topa-se com o posicionamento do editor:

“... compreendendo a História como a "ciência do Homem", segundo o conceito de Lucien Febvre (9), estamos certos de que não nos faltará o apôio de quantos, no âmbito universitário ou fora dele cuidam de assuntos de fundo histórico.

A largueza do nosso campo de ação permitirá acolhimento de trabalhos sobre quaisquer dos setores da História: econômica, social, política, religiosa, literária, filosófica, científica..." (10).

\section{- Objetivo concretizado, mas como?}

Consulte-se os Indices da Revista de História: volume I (do $\mathrm{n}^{\text {\% }}$ 1 ao 40) - São Paulo, 1966; volume II (do no 41 ao 80) - São Paulo, 1970 e o volume III (do no 81 ao 120 ), em processamento editorial .

Ainda. A Coleção da Revista de História, ora de 50 volumes, cujos títulos estão na contra-capa de cada número, montados na linha do periódico matriz: Annales (Economie, Société, Civilisations).

Mais ainda. Os Anais dos Simpósios bi-anuais da ANPUH (Associação Nacional dos Professores Universitários de História). O VII Simpósio realizado em Belo Horizonte, durante a Semana da Pátria de 1973, com a abordagem do tema fundamental: A Cidade e a História, instrumenta 3 volumes, com mais de 2.000 páginas; que serão entregues aos seus assinantes na véspera do VIII Simpósio que se realizará em Aracaju, de $1^{\circ}$ a 7 de setembro de 1975.

(8). - Idem.

(9). - FEBVRE (Lucien), $O$ homem do século $X V I$ (conferência), Revista de História, São Paulo I (1), 1950.

(10). - Simões de Paula (Eurípedes), Nosso Programa, idem. 
Está aí um registro assim por alto, nem sequer tocando as estruturas.

- Trabalho de equipe?

Não. Mil vezes năo. Registre que é:

"o esforço, a tenacidade, o idealismo mais, ... o suor de um só homem. Exageradamente fora de série...".

Registre-se tambem que e, talvez por tudo isso e mais algo, indefinivel, ele, Eurípedes Simões de Paula, o diretor da Revista de História, o organizador dos Indices, da Coleção, dos Anais - ele próprio presidente da ANPUH, - vem sendo amado e respeitado por aquela gente, desde mundo de Deus.

Atesta-o a presença dos 48 colaboradores do Número Jubilar I, o qual poderia autenticar tanto a obra como o seu criador. Discretamente. Bem dentro do parâmetro traçado pela sua organizadora quem assina esta nota.

Informe-se que dos intelectuais estrangeiros e nacionais convidados não se anotou nenhuma recusa formal. Se não estão alí, todos os que se planejou reunir, culpe-se a precariedade dos endereços, calcados em algumas das cartas devolvidas ao remetente.

Operacionalmente, dizem por aí, haver colaborado na "Revista do Eurípedes", chegaria a dar nivel, enriquecer currículos universitários.

Enquanto a moçada analisa aqui e acolá, os estudantes mais cautelosos, começam os fichamentos, avant-première, dos seminários de estudos. Programados. Espontâneos. Eles, os mais numerosos, os mais sérios, os mais atuantes leitores.

Uma senhora faz 100 anos lá na Bahia.

Uma revista especializada, veicula o $100^{\circ}$ número aqui em São Paulo.

- Onde a interdependência?

- Não se trata, Deus nos livre se o fosse, de manchetes sensacionais, de capítulos de novelas a ser escritos:

Muito menos do início de uma série de biografias promocionais, laudatórias. De gente. De instituições.

Risco que se não poderia correr, menos ainda nesta época de marcante contestação. Que atinge, tambem, o modelo da Antiguidade Clássica, em que o gênero biográfico era super-valorizado. No extre- 
mo oposto, agrupam-se os mais estremados, que rotulam a biografia de peça acessória, ou a ignoram.

"Nem oito, nem oitenta", argumenta a direção desse periódico, formando ao lado daqueles que endossam a concepção de que:

“... a biografia pode ser altamente interessante para o historiador, na medida em que permite compreender o estilo geral da vida da época, ou ainda uma atitude humana particularmente expressiva diante de certos valores moraes ou sociais" (11).

Recordando a lição do Mestre uspiano, uma tentativa de análise:

\section{MARIAZINHA MESSEDER}

Salvador. BA. 100 anos

1 vida

\section{Centenário}

(dezembro, 1974)

\section{REVISTA DE HISTORIA}

São Paulo. SP. 100 números 1 instituição.

Com a postulação acima a sugestão de inserir o centenário de d. Mariazinha no contexto da época, através de um eventual mediador, a Revista de História. Concientizando-se de que, colocar problemas seria uma outra maneira de concluir.

Entretanto, elementos novos acionaram a retomada da análise histórica. Ei-los: o facsimile, autenticado de um documento precioso (12). Uma das muitas mensagens impressas na oficina tipográfica da Abadia de Santa Maria, valorizada com o autógrafo da aniversariante centenária (13). Mais uma renda de crochet; confeccionada por aquelas mãos, incansavelmente laboriosas (14) .

Foque-se a certidão de batismo que o clichê reproduz. Apenas 11 linhas datilografadas, mais a assinatura do responsavel, sob o selo de autenticação que é o mesmo do papel, timbrado, da Secretaria Eclesiástica de São Salvador da Bahia. Instrumenta o seguinte fato:

"Certifico, que, do livro n. 19 página 65 de batizados da freguesia de S. Pedro, consta o assentamento do teor seguinte: / -

(11). - GOLDMANN (Lucien), Ciências Humanas e Filosofia. (Trad. de Lupe Cotrim Garaude e J. A. Gianotti), São Paulo, Difusão Européia do Livro, 3a. edição, pág. 24.

(12). - Certidão de batismo de Maria da Glória (28 de março de 1875) expedida pela Secretaria Eclesiástica de São Salvador da Bahia.

(13). - Maria da Glória Câmera Messeder. 15 de Dezembro de 1974.

(14). - Com o recado de que a cor amarela, sempre preferida, é a cor da Divindade (de todas as cousas belas, todas as flores tem um ponto amarelo). 


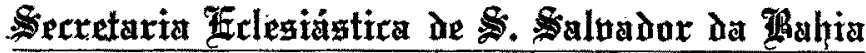

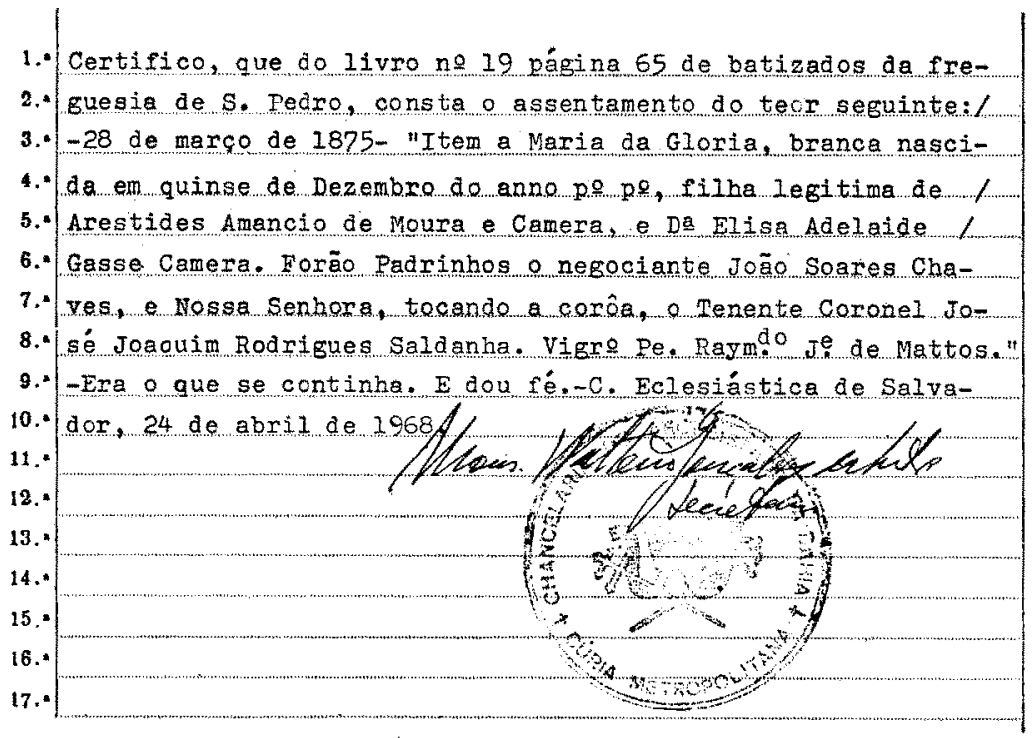


28 de março de 1875 - "Item / Maria da Gloria, branca nascida em quinse de Dezembro do anno $\mathrm{p}^{\circ} \mathrm{p}^{\mathrm{\rho}}$, filha legítima de / Aristides Amancio de Moura e Camera, eDa. Elisa Adelaide Grasse Camera. Forão Padrinhos o negociante João Soares Chaves, e Nossa Senhora, tocando a corôa, o Tenente Coronel José Joaquim Rodrigues Saldanha, Vigr ${ }^{\circ}$ Pe. Raym.do J.e. de Mattos." - Era o que se continha. E dou fé. Curia Eclesiastica de Salvador.

a) Mons. Walterio Gonçalves....... (15). Secretario.

Sente-se um texto de riqueza insuspeitada. Com mais de uma vertente. Leitura ideológica. Análise estrutural. Preocupação fundamental o relacionamento da mensagem, aos valores institucionais de uma época bem caracterizada. Bem próxima no tempo histórico. Com uma bem outra utensilagem mental, na trilha aberta por Lucien Febvre (16) .

Especificamente ao se focar o ângulo cultural do último quartel do século XIX. Na vertente em que os homens tinham a sua etiqueta burocrática, através das certidões individualizantes, de títulos de proprietários de terras, fornecidas pelos arquivos paroquiais (17). Esse sentido cultural dos arquivos eclesiásticos para a tentativa de interpretação de alguns aspectos do passado histórico do Brasil, vêm sendo enfatizado, ao que se saiba, a partir do III Simpósio da Associação Nacional dos Professores Universitários de História (ANPUH), realizado em 1968 (18).

(15) . - Por ora não se conseguiu decifrar a assinatura completa do Monsenhor Secretário da Cúria Eclesiástica de São Salvador.

(16). - FEBVRE (Lucien), Le problème de lencroyance au XVIe siècle ( $L$ a religion de Rabelais) - coloca, entre outras problemáticas, a da eventual possibilidade do ateismo no século XVI. Posicionamento que equivale a uma revolução nos métodos da História das Mentalidades. Porquanto à história "evénementielle", à história amarrada ao conhecimento, coloca à História instrumental, em que se objetiva estudar a estrutura mental de uma época. Seria o estudo de que ele próprio chama, utensilagem mental de uma época.

(17). - Compare-se: Constituiçáo Politica do Império do Brasil. Rio de Janeiro, Typ. Nacional Títulos $2^{\circ} 8^{\circ}, 3: 4: 5: 41 ; 1824$ e a Constituiçôes da República Federativa do Brasil (com as emendas constitucionais - Título II, art. 145) Brasília, D. F. 1972. Aqueles que praticam o artesanato da História sabem da fundamental importância dos arquivos eclesiásticos, para a abordagem do passado histórico de nossa terra, pois o registro civil, foi criado pelo art. 2 da lei n. 1829, de 9 de dezembro de 1890. Enquanto que o Código Civil Brasileiro, promulgado em 1916 pelo então Presidente Wenceslau Braz, entrou em vigor a partir de 1 de janeiro de 1917.

(18). - SIMÕES DE PAULA (M. R. C. R.), As fontes primárias existentes no arquivo da Cúria Metropolitana de São Paulo (Capital) Anais do III Simpósio da ANPUH, São Paulo, 1966. 
Outrossim, numa perspectiva mais ampla, lembre-se a advertência de Cinzio Violante, professor catedrático da Universidade de Piza, numa das sessões do XII Congresso Internacional de História, realizado em Viena d'Áustria, em 1965. Oportunidade em que defendeu a tese da operacionalidade dos arquivos paroquiais, tambem para a compreensão da mentalidade dos camponeses, em suas andanças do campo para o centro urbano, sede da paróquia (19) .

Reflexões assim foram surgindo, num atropelamento de imagens, no momento em que Kadja Cristina Grimaldi Guedes, pós-graduanda da área de História Social do Departamento de História da Universidade de São Paulo, ora portadora das lembranças acima destacadas, confidenciava suas próprias impressões. Captadas pela sensibilidade da jovem bahiana que, familiarizada com os cientistas sociais, soube encaminhar a entrevista para algumas datas rupturas da História do Brasil . Ei-las, passíveis de crítica, aceitas a priori, 1888, 1889, 1929.

Assim conseguiu um emocionante flash sobre a vida dos escravos, em que ainda menina, Mariazinha recusou locomover-se na cadeirinha de aluguel, amarrada nas costas dos pretos velhos.

Lembrou-se das festas da Proclamação da República Federativa do Brasil, na então Província da Bahia, apesar de notícias desencontradas, conflitivas sobre o evento.

A crise sócio-econômica de 29 , encontrou-a na cidade do Rio de Janeiro, onde residiu dezenas de anos (1915 a 1929) em função da atividade comercial do seu marido que, de corretor geral, chegou a ocupar o cargo de Diretor da Associação Comercial da Bahia.

O diálogo não foi, nem poderia haver sido, pautado por uma cronologia rígida.

Dona Mariazinha lembrou-se que esteve na Europa, logo depois de casada,

"Em 1894, lembrou-lhe a filha solícita, que tambem procurou ajudar na lembrança das impressões de Lisboa, Roma, Londres, Paris e, mais saudosamente, dos santuários de Lourdes e de Fátima. Supreendentemente foi a própria "Vó" centenária quem se lembrou do nome de duas de suas ex-professoras: Elisa Ramos Costa e Maria Amália Ramos Costa, do Colégio do Pontão da Piedade".

(19). - Cf. Eurípedes Simões de Paula, Algumas considerações em torno do XII Congresso Internacional de Ciências Históricas, in "Revista de História",

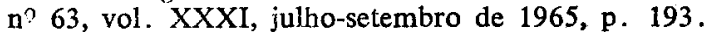


Aqueles que ouviram a narrativa de Kadja, repetida aqui e acolá, acabaram por sentir o imperativo de um projeto de pesquisa. Operacional. Numa perspectiva diacrônica cuja etapa primeira seria a busca de depoimentos, informações, sugestões, colhidos na intimidade da familia, em mutirões de trabalhadores, nos relatos dos cronistas de localidades bem caracterizadas. Discretamente, com equipamento de gravadores camuflados. Nem seria preciso que se buscasse encontrar a maneira das "gincanas" - velhos de cem anos, ou quase. Estudar-se-ia, selecionar-se-ia uns poucos valores capazes de detectar aquela gente portadora de uma mensagem, de um código. Que numa retomada de análise, procurar-se-ia encaixar no contexto da própria vida.

Tendo presente que a Revista de História vem passando por reformas estruturais, poder-se-ia sugerir que, nas sessões existentes ou não, eventualmente programadas, houvesse mais uma abertura. Para a pulsação de um instrumento de pesquisa vinculado diretamente à comunidade, a preservação de seus autênticos valores. Sejam os chamados dialetos caipiras, manifestações culturais tradicionais. Ou e, mais ainda, depoimentos de gente mesmo.

Instrumento de trabalho que não é, nem precisaria fosse inédito. Pois já se conhecem os Arquivos Falados. O dimensionamento da História Oral. Da Memória Histórica. Conta-se que em recente seminário realizado na antiquíssima Universidade de Toulouse, advertência houve, para uma História do Temporo Espacial.

Argumentar-se-ia apenas no imperativo de um planejamento de roteiros. Ou melhor de efetiva interdisciplinariedade de trabalho, que as páginas desse periódico trimestral, poderiam reunir, um outro epicentro operacional.

Em chegando ao ponto final destas notas, tentar-se-ia responder, com uma ousadia sem limites, ao poeta maior que (20):

"A uma senhora que completa cem anos" não se dá nenhum presente. Pois é ela própria, neste caso específico, dona Mariazinha Messeder, quem está dando a toda gente, à Revista de História, periódico trimestral, de número centenário, o presente de uma idéia, uma grande idéia.

(20). - DRUMMOND DE ANDRADE (Carlos), A uma senhora em seu aniversário. Poesias Completas e Prosa. Rio de Janeiro, Biblioteca Luso-Brasileira, 2a. ed. pág. 1258; 1973.

(“... A uma senhora que completa cem anos, que presente se deve dar: os descobrimentos no espaço? Os descobrimentos no coração do átomo? Canções novas? Filosofia mais sábia que as já tentadas e desaprecidas? ...". 